\title{
ENTREVISTA CON MARIO VARGAS LLOSA
}

Jaime Perales*

Usted conoció intelectualmente a Octavio Paz en la década de los cincuenta cuando leyó Piedra de Sol. ¿En qué momento conoció a Paz personalmente y cómo fue que lo invitó a colaborar en la revista Plural, que posteriormente se convertiría en Vuelta?

Conocí personalmente a Paz en Londres, probablemente en el año 68 en casa de Carlos Fuentes, en una cena que dio Carlos para Octavio y Mari Jo, que estaban de paso en Londres. También se encontraban Guillermo Cabrera Infante y algunos jóvenes escritores mexicanos cuyos nombres no recuerdo.

\section{José Emilio Pacheco...}

No, no estaba José Emilio. Ninguno de los que conozco yo, era un grupo bastante amplio de aspirantes a escritores muy jóvenes que estaban de paso. En fin, era un grupo. Y bueno, me dio mucho gusto conocer a Octavio, porque yo lo había leído bastante y lo admiraba mucho, como poeta y ensayista. Creo que desde esa época Paz tenía ganas de publicar una revista. Incluso cuando algún tiempo después nosotros publicamos en París una revista de vida muy efímera que se llamó Libre...

Cuatro números, me parece...

* Egresado del ITAM, realiza estudios de posgrado en Georgetown University. 
Jaime Perales

Exactamente. Asociamos, por supuesto, a Octavio Paz en el proyecto y recuerdo muy bien una carta de Octavio, me parece que a Julio Cortázar, en la que criticaba mucho el número de Libre que acababa de leer; se sentía muy decepcionado, decía que su proyecto se había desfigurado y que ésa no era la revista que necesitaba América Latina. No recuerdo exactamente las críticas que hacía, pero al poco tiempo apareció Plural. Desde el principio la revista tuvo un alto nivel de calidad artística y una línea política bastante clara. No estoy muy seguro si coincidió o no con la aparición Plural, pero estuvo muy cerca el famoso caso Padilla, hecho fronterizo, en cierta forma, en la historia política de los intelectuales en América Latina y en la que Plural tuvo una posición muy definida.

Las revistas intelectuales, o fundadas por intelectuales, han nacido debido a una función específica de la situación cultural y política de la época: Revista de Occidente difundió en lengua española la gran cultura alemana de principios de siglo; Partisan Review fue una publicación cultural de izquierda que criticó el estalinismo; Sur estableció estrechos vínculos culturales con América Latina y Europa y Mundo Nuevo fue llamada "la gran revista" que promovió el Boom en toda Latinoamérica. ¿Cuál sería la función o funciones específicas que Vuelta ha tenido en los últimos veintitrés años?

La gran tarea de Plural, y luego de Vuelta (en realidad es la misma revista aunque cambiada de nombre, ya que el espíritu fue el mismo: La revista de Octavio Paz. Y sus principales colaboradores fueron los mismos. No hubo ninguna escisión, hubo simplemente un despojo del título) ha sido, por una parte, servir de tribuna a una serie de escritores mexicanos y latinoamericanos que encontraron un órgano de expresión de muy alto nivel para la poesía, para la narrativa y el ensayo y un territorio en el cual cotejar sus simpatías y sus diferencias. Creo que en este sentido, desde el punto de vista estético, la revista ha estado muy abierta a la pluralidad.

También ha sido una ventana magnífica de lo que ocurría en otras regiones culturales del mundo, tanto en Plural como en Vuelta se ha traducido mucha poesía, ensayo, relatos del inglés, del francés y de otras 


\section{ENTREVISTA CON VARGAS LLOSA}

lenguas, como el alemán y el italiano. La revista ha reflejado la gran curiosidad universal que caracteriza al pensamiento de Octavio Paz.

Por otra parte, junto con la función literaria y artística, ha tenido un papel muy importante desde el punto de vista de las ideas y de la política. La revista ha sido muy claramente, desde un principio, defensora de la opción democrática, muy crítica de todos los autoritarismos y totalitarismos. Es una de las revistas que ha tenido menos complejo de inferioridad frente a los comunistas y al marxismo, por ejemplo, a los que se enfrentó desde un primer momento con mucha claridad y desde una perspectiva democrática. Es una de las cosas que hay que agradecerle más a Plural y a Vuelta. Hoy en día eso no se aprecia bastante porque hay un consenso, o casi, pues una mayoría de latinoamericanos -incluso en el campo intelectual- defienden la opción democrática. Es muy difícil para los jóvenes, como usted, imaginarse lo que ocurría hace veinte o treinta años en el campo ideológico en América Latina, donde defender la opción democrática era ser automáticamente descalificado por el medio intelectual, arrinconado en un extremo; calificado de reaccionario, conservador, antiprogresista y casi expulsado de la historia. Esto se debe a que la izquierda marxista dogmática ejercitaba una inquisición tanto ideológica como ética.

Bueno, Plural y Vuelta les sirvió a escritores como yo, que desde los años sesenta teníamos una actitud crítica frente al socialismo, al marxismo, al colectivismo y al estatismo. Las revistas fueron realmente un enorme estímulo, una magnífica trinchera para combatir, sin tener que recurrir a los órganos de expresión efectivamente reaccionarios o conservadores. Creo que en ese sentido la labor de Paz y del grupo de colaboradores que trabajaron con él en estas dos publicaciones ha sido valiosísimo. En este campo quizá ambas revistas han producido el más grande impacto.

Pero usted no cree que en Plural, a diferencia de Vuelta, hubo una especie de búsqueda en el sentido político. Por ejemplo, hubo cierta simpatía por algunos regímenes de carácter estatista, como el de Velasco Alvarado en Perú. Se publicaron artículos de Eric Hobsbwam, e incluso de usted, que elogiaban a este tipo de regímenes que ideológicamente serían... 
Jaime Perales

Bueno, yo creo que ni Plural, ni luego Vuelta, han sido revistas intolerantes. En ellas se han encontrado muchas voces disidentes. No sólo en el campo artístico, sino en el campo político, en el cual hemos discutido muchas veces sobre diversas opciones. Yo recuerdo que salió el libro de Jorge Edwards a comienzos de los años setenta...

\section{Persona non grata.}

Sí, Persona non grata, del que en la misma revista hubo distintas lecturas, como el caso de Emir Rodríguez Monegal. Yo recuerdo también un ensayo muy polémico e interesante sobre El Salvador escrito por Gabriel Zaid, "Colegas enemigos". La revista ha defendido posiciones democráticas, pero incluso abrió sus puertas a personas no muy democráticas. En la época de Velasco, colaboraron muchos velasquistas. En la época de la dictadura militar peruana, Julio Ortega, empleado de la dictadura, colaboró en la revista. La revista ha sido bastante abierta dentro de una línea que no podía confundir a nadie. La propia posición frente al gobierno mexicano ha sido objeto de controversias en el seno de la misma revista. ¿No es verdad? Ésa es una manera práctica de demostrar que la revista es democrática, tolerante si hacer concesiones sobre los principios, pero admitiendo el debate y la crítica.

En la década de los ochenta Vuelta incrementó de manera sustancial sus artículos políticos debido al papel protagónico de las democracias en América Latina. Vuelta idealizó a la democracia como una variable moral en la vida de las sociedades en desarrollo. Diez años después se puede observar que la transición política en América Latina ha sido lenta, dolorosa y, en ocasiones, poco efectiva. En los casos particulares de las experiencias de Brasil, Venezuela, Perú y Haití ino cree usted que la actitud de considerar a la democracia como un valor en sí es una visión reduccionista dada la extrema complejidad de Latinoamérica?

No, creo que no, creo que ésa es una visión inexacta. Yo creo que la democracia ha funcionado en América Latina. Incluso en los casos más trágicos que se puedan mencionar, los de Brasil y Venezuela, en donde la democracia ha sido incapaz de traer beneficios concretos en lo económico, no ha eliminado la corrupción y hasta la ha fomentado; sin embar- 


\section{ENTREVISTA CON VARGAS LLOSA}

go, los mecanismos democráticos han funcionado. En el caso de Brasil se logró expulsar a un presidente corrupto, y a pesar de todo el sistema no ha sido reemplazado por los cuarteles. En el caso de Venezuela ha habido dos intentos de golpe, mucha corrupción, ineficiencia escandalosa, pero el sistema democrático no se ha desplomado; esperemos que no se desplome.

En el Perú sí, en cambio, el sistema se ha desplomado, pero porque fue traicionado desde arriba: el Presidente, quien debería garantizar la supervivencia del sistema, le asestó una puñalada por la espalda en complicidad con militares felones. Es verdad que la crisis en el Perú era tremenda, que había una enorme confusión, inseguridad, desconcierto, por la inflación, el despilfarro que había dejado el gobierno anterior. Quizás eso explica que el golpe tuviera simpatizantes a nivel popular. Pero salvo el caso del Perú, donde se puede hablar de un golpe de estado antidemocrático con cierto respaldo ciudadano, no ha habido ningún otro. En Guatemala, cuando el señor Serrano intenta imitar a Fujimori, fracasa porque se levanta el país entero: se levantan obreros, campesinos, empresarios, las instituciones, y le paran el golpe.

En el caso de Haití no hay ningún tipo de apoyo popular para la dictadura. Es una oligarquía que conspira con el ejército y que se sostiene a base de terror. Mal que mal, la democracia con todas las imperfecciones y deficiencias, que son comprensibles en América Latina, porque es un continente sin tradición democrática, está sobreviviendo...

\section{¿Sigue siendo el gobierno menos malo?}

Sigue siendo del gobierno menos malo. Ésta no es mi interpretación, creo cue éste es el consenso que existe en América Latina: que, a pesar de todo, la democracia es preferible. Entonces, yo no soy tan pesimista, no creo que haya habido una idealización de este sistema. Lo que pasa es que la democracia es un proceso. No hay democracias perfectas... Hay democracias en distinto grado de imperfección y la imperfección en América Latina lógicamente tiene que ser muy pronunciada. Pero me parece que en lo político Plural y Vuelta han sido bastante objetivas en esto y no ha habido ningún tipo de mistificación, idealización de gobiernos ineficientes o corruptos. Se han hecho muchas críticas, también han habido errores de información, pero esto es absolutamente inevitable. 
Jaime Perales

\section{¿En qué cree que ha fallado Vuelta?}

A la hora de hacer críticas se pueden hacer muchas, pero lo importante es que en el balance, lo positivo es inmensamente superior a lo negativo. Quizá la lucha dentro del propio medio intelectual mexicano ha hecho que Vuelta no pudiera abrirse lo suficientemente a todos los matices de la intelectualidad mexicana. Esto es algo que se puede lamentar, pero es muy difícil que no sea así, cuando uno piensa que precisamente por sus posiciones y por su prestigio y éxito, tanto Plural como Vuelta han sido ferozmente atacadas. El hecho mismo de que Plural se tuviera que convertir en Vuelta da una idea de hasta qué punto estuvo hostilizada. En parte por razones políticas, pero también por las envidias, emulaciones y resentimientos que siempre envenenan la vida intelectual; Plural y Vuelta han padecido mucho ese tipo de problemas, pero han tenido también mucho apoyo, porque sin él, no se explicaría su supervivencia... Las revistas literarias mueren con enorme facilidad -incluso en países muy desarrollados - y la supervivencia extraordinaria de esa revista es algo que tenemos que agradecer.

Las revistas tienen su tiempo de caducidad. ¿Usted cree que Vuelta en algín momento debe de morir?

Mire creo que no vale la pena jugar al adivino. Hasta ahora la revista juega un papel principalísimo. No hay una revista dentro de la lengua española que pueda competir con Vuelta; hay otras pero todas tienen una radiación muchísimo menor, una significación más local. De tal manera que creo Vuelta goza de una muy buena salud.

¿No hay alguna otra revista que pueda competir con Vuelta?

No conozco ninguna revista que pueda competir con Vuelta, y esto no quiere decir que no haya, pero la verdad, desde el punto de vista cultural no conozco ninguna.

¿Una buena "dictadura cultural" como la que ejerció por ejemplo, Les Temps Modernes de Sartre? 
Bueno... hay revistas que en algún momento encarnan un momento cultural. La Revista de Occidente de la época de Ortega, La Nouvelle Revue Francaise, en la época de Gide o de Paulhan, Sur en la de Borges. Naturalmente que han sido símbolos de una época. Creo que Vuelta y Plural son muy representativas de lo que ha sido este período que comienza con los alborotos del Mayo de 68 y que se cierra con el desplome del totalitarismo, de los estados socialistas, con la democratización en América Latina y, por último, con las convulsiones que está viviendo ahora México. Creo que es una revista que ha vivido este período tan tumultuoso, tan turbulento, que en el futuro los historiadores de la cultura van a tener que ir a consultar Plural y Vuelta para saber cómo se vivieron todos estos acontecimientos desde una perspectiva latinoamericana.

A raíz del primer Encuentro Vuelta celebrado en México hace tres años se pueden distinguir dos posiciones interesantes con respecto a la conexión entre capitalismo y democracia. Por una parte autores como Daniel Bell, Irving Howe y el propio Octavio Paz han tenido una actitud crítica y de cierta reserva con respecto a esta conexión mágica y polémica. Por otra parte se encuentra la suya, de defensa. Dada la experiencia de algunas multinacionales, como la ITT Company en Chile en la década de los setenta, que han atentado contra la democracia en Latinoamérica ino cree que esta relación en ocasiones es exagerada y perniciosa?

No, creo que hacer esa crítica es confundir el efecto con la causa. Adam Smith dijo una cosa muy gráfica sobre lo que es una empresa capitalista y lo que es un empresario. Si un empresario está bien encarrilado, es decir, si está colocado sobre las reglas de juego del mercado libre, competitivo, se convierte en una fuerza creativa extraordinaria. Crea riqueza, crea trabajo y es un factor de progreso y prosperidad para una sociedad. Ahora, si ese empresario y esa empresa no son colocados sobre los rieles del mercado libre, sino por ejemplo, sobre un sistema de tipo mercantilista, en el cual el éxito no depende de los consumidores sino de los privilegios que concede el poder político como prebendas, monopolios, divisas a precios preferenciales, etc., entonces, esas reglas de juego inmediatamente se convierten en las reglas con las que funcionan el empresario y la empresa. Naturalmente, esa empresa se convierte en un 
Jaime Perales

factor extraordinario de corrupción, porque si se trata de corromper para triunfar, las empresas van a corromper funcionarios. Ahora, no hay que confundir el efecto con la causa: quien fija las reglas del juego no deben ser las empresas, debe ser el poder político en manos de los representantes elegidos. Quienes fijan las reglas del juego son los estados, son los gobiernos.

Entonces, hay que pedir a los estados y los gobiernos que fijen leyes y reglas de juego que impidan a las empresas ser perjudiciales, que conviertan a las empresas en unos instrumentos fundamentalmente creadores de riqueza, trabajo y prosperidad. Ése es el sistema que, donde ha funcionado, ha traído no solamente prosperidad a los pueblos, sino que ha consolidado las instituciones y ha dado estabilidad a la democracia. El sistema ha sido imperfecto, desde luego, y siempre va a ser imperfecto, pero donde menos imperfecto es, funciona mejor. La relación entre empresa privada, economía de mercado y democracia es inevitable. No hay ninguna alternativa, ¿cual sería la alternativa? Todos los gobiernos autoritarios, totalitarios, desde el punto de vista han sido ineficientes, han sido corrompidos, y al final han sido rechazados brutalmente por los propios pueblos.

14 La relación entre intelectuales y Estado en México es muy cercana. La revista Vuelta ha sido eriticada por tener una relación no con el Estado sino con la empresa privada, tal es el caso de la televisión en México, la cual representa un poder igual de grave que el Estado. ¿No cree usted que la relación entre Vuelta y la televisión en México le resta cierta distancia eritica a la revista publicada por Paz?

Yo no estoy en condieiones de pronuneiarme sobre algo que no conozeo. Yo no sé cual es la relación de Vuelta con Televisa. Asistí a un congreso que, efectivamente, fue patrocinado por Televisa, pero lo que puedo decir de ese congreso es que ninguna de las personas presentes tuvimos la menor linitación para expresarnos $y$, a usted le costa, yo me exprese con total libertad (ineluso a disgusto de los propios organizado. res del evento). Mi idea es que un intelectual debe tratar de mantener su independencia del poder político y de los otros poderes también. Naturalmente que esto no siempre es posible, yo lo sé, desde luego, pero 
mientras más independiente se es, se escribe con mayor libertad. De esto no me cabe ninguna duda.

Como intelectual latinoamericano icree que exista alguna diferencia entre los intelectuales en Latinoamérica y en México?

Sí, hay diferencias. La diferencia es que el PRI ha sido un sistema muy exitoso en cooptar a la clase intelectual. Lo ha hecho de una manera muy novedosa en relación con los otros sistemas autoritarios y totalitarios, que generalmente cooptan al intelectual degradándolo, convirtiéndolo en un instrumento, al que se le exige el servilismo y, a veces, la abyección. La habilidad del PRI ha estado más bien en sobornar muy sutilmente a la clase intelectual ayudándola, subsidiándola, concediéndole trabajos fantasmas que le permitían sobrevivir, ino es verdad? Incorporándola a su servicio diplomático y a cargos públicos que muchas veces eran formas disimuladas de subsidio, sin exigir del intelectual ese tipo de servilismo extremo, característico por ejemplo de las dictaduras comunistas. En muchos casos esas reglas de juegos sutiles al intelectual mexicano le permitían ejercitar la crítica y hasta le pedían que lo hiciera. Una crítica, claro, hecha dentro de ciertas reglas, de tal manera que el sistema pudiera mostrar al mundo, y a la propia sociedad mexicana, que era un sistema abierto, que respetaba la disidencia. Ha sido una manera verdaderamente diabólica, pero muy exitosa, de neutralizar a la clase intelectual.

\section{¿Eso no pasa en ninguna parte de America Latina?}

Eso no pasa en ninguna parte del mundo. Los gobiernos autoritarios o tienen un gran desprecio al intelectual y no se interesan absolutamente en él para censurarlo porque no lo consideran peligroso, o lo compran y lo convierten en un elemento instrumental, que envilece y degrada al intelectual. En esos paises el intelectual est en la disyuntiva de ser un cortesano o un disidente. En Méxleo no ha oeurrido esto; en México los intelectuales que han sido castigados son aquellos pocos que el rẻgimen no ha podido neutralizar. Un Revueltas, por ejemplo, al que mandaron a la círeel, es un caso muy excepeional. El PRI no ha querido mandar intelectuales a la eareel; lo ha hecho cuando no ha tenido más remedio, cuando eran excesivamente rebeldes. Ha preferido siempre sobornarlos 
Jaime Perales

de una manera delicada. Los intelectuales tienen que vivir, entonces les crea trabajos; tampoco los hace ricos, les permite sobrevivir dentro de una dependencia que simplemente los limita. Les da coartadas, les ha permitido siempre el izquierdismo, ha sido una de las astucias del PRI. El intelectual mexicano podía ser muy izquierdista con respecto al resto del mundo, y mantenido por el Estado. Eso era perfecto. Al PRI eso le gustaba y le servía mucho porque daba al mundo la imagen de que era un gobierno muy progresista. Los intelectuales mexicanos siempre estaban a la vanguardia del combate: Contra el imperialismo, contra el colonialismo, y al mismo tiempo vivían de los sueldos del PRI. Entonces, eso ha creado esa situación anómala. Lo interesante es que esto no ha sido concebido por una mente maquiavélica, ha sido resultado de ese sistema tan sutil, tan complejo que viene de la sabiduría de un país antiguo, pero al mismo tiempo éste es un mecanismo aterrador, porque es una manera muy eficaz de neutralizar al intelectual y de ponerlo al servicio de un régimen.

Naturalmente, han habido intelectuales que han sido capaces de romper esto, pero no es muy fácil. Ha habido intelectuales que se han visto ante la alternativa de romper con el régimen...

\section{¿Como Paz?}

Como Paz que, bueno, en el caso de la matanza de Tlatelolco reaccionó admirablemente bien. Pero el sistema es un sistema muy exitoso, el intelectual mexicano lo instrumentalizó de una manera que es muy difícil, para el propio intelectual, darse cuenta de la manipulación de la que es víctima.

¿Vuelta es acaso una sobreviviente de la llamada crisis del intelectual en el mundo pronosticada por Russell Jacoby, en su libro The Last Intellectuals? De igual forma, iusted cree que el intelectual en América Latina es una clase que se está extinguiendo?

Mire, no lo sé, no me atrevo a hacer ese tipo de pronósticos, yo creo que el intelectual en América Latina ha tenido un papel bastante limitado hasta ahora. Por esta razón no creo que ese papel se esté deteriorando mucho más, porque nunca fue demasiado importante. Pero creo que 


\section{ENTREVISTA CON VARGAS LLOSA}

cuando hay crisis, se ve que hay un rol para el intelectual. Como ahora en México con la crisis de los últimos meses, con Chiapas y el asesinato de Luis Donaldo Colosio. Esto ha dado otra vez al intelectual protagonismo y ha surgido un debate abierto, en el que participan muchos intelectuales. Aunque la polémica es feroz, lo interesante parece ser la aspiración común de los intelectuales de que se democratice el sistema. Mi impresión es que por debajo de sus tremendas divisiones sobre eso hay un común denominador...

¿Un consenso?

Un consenso: La democracia. 